\title{
Alcohol-induced hypertension: an important healthcare target in Belgium
}

\author{
F. Collart ${ }^{1}$, P. de Timary ${ }^{2}$, G. Dom ${ }^{3}$, B. D. Dor ${ }^{4}$, D. Duprez ${ }^{5}$, J.-P. Lengelé $^{6}$, \\ F. Matthys ${ }^{7}$, H. Peuskens ${ }^{8}$, J. Rehm ${ }^{9}$, P. Stärkel ${ }^{10}$
}

${ }^{1}$ Department of Nephrology, CHU/UVC Brugmann, Brussels, Belgium, ${ }^{2}$ Department of Psychiatry, Cliniques Universitaires Saint-Luc, Brussels, Belgium, ${ }^{3}$ Collaborative Antwerp Psychiatric Research Institute (CAPRI), Antwerp University, Wilrijk, Belgium, ${ }^{4}$ Department of Addictions, Centre Hospitalier Spécialisé L'Accueil, Lierneux, Belgium, ${ }^{5}$ Cardiovascular Division, University of Minnesota, Minneapolis, MN, USA, ${ }^{6}$ Department of Cardiovascular Pathology, Cliniques Universitaires Saint-Luc, Brussels, Belgium, ${ }^{7}$ Department of Psychiatry, Universitair Ziekenhuis Brussel, Vrije Universiteit Brussel, Belgium, ${ }^{8}$ Department of Psychiatry, Universitair Ziekenhuis Leuven, Belgium, ${ }^{9}$ Centre for Addiction and Mental Health, Toronto, ON, Canada, ${ }^{10}$ Department of Hepato-Gastroenterology, Université Catholique de Louvain, Cliniques Universitaires Saint-Luc, Brussels, Belgium

Excessive alcohol intake is one of the leading causes of premature death in Europe and particularly in Belgium. Belgian people are consuming more alcohol per year than the European average. It is well established that excessive alcohol consumption is a significant predictor of the development of hypertension (HTN). Two million adults in Belgium suffer from HTN and this number will increase to three million by 2025 . Less than $50 \%$ of Belgian people treated for HTN are well-controlled. Alcohol reduction in patients with HTN can significantly lower systolic and diastolic blood pressure. After reviewing the epidemiology of HTN and alcohol disorders in Belgium, this paper will focus on the rationale for alcohol screening and brief intervention in primary care. It will also describe the barriers to alcohol screening, and what could be the benefits of alcohol screening for our healthcare system. The authors believe that early identification through alcohol screening and brief intervention in general practice can help to improve the management of patients with HTN, to reach the targets of the WHO Global Action Plan, i.e., a 25\% relative reduction in the risk of premature mortality from cardiovascular diseases, cancer, diabetes or chronic respiratory diseases. They are also convinced that this would allow achieving major healthcare savings.

Keywords: Alcohol screening, Harmful alcohol use, Alcohol use disorder, Hypertension, Primary care

\section{Hypertension and Alcohol: risk Factors for Burden of Disease}

Non-communicable diseases (NCDs) are responsible for the majority of premature deaths across the world. $^{1,2}$ For this reason, in 2013, the World Health Organization (WHO) set an overall goal of achieving a significant reduction in overall mortality from NCDs by 2025. ${ }^{1}$ The main objective was a $25 \%$ relative reduction in the risk of premature mortality from cardiovascular diseases, cancer, diabetes or chronic respiratory diseases; supported by the reduction of risk factors as well. Among the risk factors, the goals were at least $10 \%$ relative reduction in the harmful use of alcohol, as appropriate, within the national context; and a 25\% relative reduction in the prevalence (or containment)

Correspondence to: Peter Stärkel, Department of HepatoGastroenterology, Université Catholique de Louvain, Cliniques Universitaires Saint-Luc, 10 Avenue Hippocrate, B-1200 Brussels, Belgium. Email: peter.starkel@uclouvain.be of hypertension (HTN), according to national circumstances. ${ }^{1}$

According to the 2014 WHO Global Report, about 3.3 million deaths $(5.9 \%$ of all deaths), were attributable to alcohol consumption in 2012. There are significant sex differences in the proportion of global deaths attributable to alcohol, $7.6 \%$ of deaths among males and $4.0 \%$ of deaths among females were attributable to alcohol. Overall, 139 million disability-adjusted life years, or $5.1 \%$ of the global burden of disease and injury, were attributable to alcohol consumption. There is also a wide geographical variation in the proportion of alcoholattributable deaths, with the highest alcohol-attributable fractions reported in the WHO European Region. ${ }^{3}$ Evidence of a causal impact of average volume of alcohol consumption was found for the following major diseases: tuberculosis, cancer, diabetes mellitus, alcohol use disorders, unipolar depressive disorders, epilepsy, hypertensive heart 
disease, ischaemic heart disease, ischaemic and hemorrhagic stroke, conduction disorders and other dysrhythmias, lower respiratory infections (pneumonia), cirrhosis of the liver, preterm birth complications and foetal alcohol syndrome. ${ }^{4,5}$

There has been a debate if alcohol may be cardioprotective by a slight increase of HDL cholesterol and by inducing a vasodilation. ${ }^{6}$ Using a macrosimulation model in England, the optimum median consumption level for drinkers was $5 \mathrm{~g}$ /day, which would avert or delay 4579 (2544-6590) deaths per year. ${ }^{7}$ However, all alcohol consumption effects for average drinking above $10 \mathrm{~g} /$ day for women and $20 \mathrm{~g} /$ day for men are detrimental. ${ }^{8}$ Harmful effects start at lower levels of average consumption for women. ${ }^{8,9}$ If we accept the stated acceptable risk of one in 1000 deaths, drinking $20 \mathrm{~g}$ pure alcohol per day exceeds this threshold, even if only the risk up to age 70 is considered (obviously, the lifetime risks for alcohol-attributable mortality will be considerably higher). ${ }^{8}$ For ischaemic and hemorrhagic stroke, the influence of alcohol consumption on mortality is much greater than the influence on morbidity, at least in women. In men, no such difference appears to exist. ${ }^{9}$ Differences in the effects of alcohol in men and women may stem from differing drinking patterns, with men more likely to engage in binge drinking, even at low average levels of consumption. These heavy-drinking occasions may lead to an increased risk of HTN for men compared with women at similar alcohol consumption levels. ${ }^{10}$

While some studies found differences between red and white wine, most well-controlled studies did not find any differences. ${ }^{11}$ Overall, the systematic reviews or meta-analyses conducted so far did not even find convincing evidence of differential effects between different beverage types, i.e., between wine, beer and spirits. ${ }^{12}$ Thus, it is likely that differences between different types of beverages on health may be due to confounding variables (i.e., certain beverage types are associated with favourable overall lifestyle patterns). ${ }^{12}$

The principal mechanisms of alcohol-induced pathophysiology are complex and will lead to increased risk for alcoholic cardiomyopathy, atrial fibrillation, blood pressure increase leading to HTN or worsening of HTN, risk for alcoholic hepatitis, liver cirrhosis and acute/chronic pancreatitis. ${ }^{13,14}$

Hypertension is the first cause of chronic heart failure, myocardial infarction and stroke worldwide, and accounts for 9.4 million deaths worldwide every year. It is a major concern for the WHO, projecting that $25 \%$ of total death will be linked to HTN in $2030 .{ }^{15}$

It is well established that heavy alcohol use will lead to a blood pressure increase and consequently is a significant predictor of the development of
HTN or worsening of HTN. ${ }^{16-19}$ The initial haemodynamic effects of alcohol have been studied: $60 \mathrm{~g}$ acutely consumed induce a reduction of $4 / 4 \mathrm{mmHg}$ (systolic/diastolic [S/D]) followed by a blood pressure rise of $7 / 4 \mathrm{mmHg}(\mathrm{S} / \mathrm{D}) 6$ hours after. ${ }^{20}$ Alcohol use is responsible for $17 \%$ of reversible HTN. The increase in blood pressure is approximately $1.5 \mathrm{mmHg}$ for each $10 \mathrm{~g}$ alcohol/day consumed and is largely reversible within 2-4 weeks of abstinence or a substantial reduction in alcohol intake. An alcohol dose-dependent increase (linear positive relationship) in the relative risk of HTN is observed whatever the type of alcohol consumed (beer, liquor, red or white wines). ${ }^{17}$ It seems that there is a lower risk of HTN among those who drank approximately daily with meals but $41 \%$ incidence in those who drink without food. ${ }^{21}$

\section{Epidemiology of Alcohol Consumption and HTN in Belgium}

With a pure alcohol per capita consumption of 11.01 per year for adults (with a peak of 141 per year between 1972 and 1980), Belgium has an alcohol consumption level that is markedly higher than the world average global amount of 6.21. ${ }^{1,3}$ If one calculates alcohol consumption only on the basis of the proportion of the population that drinks alcohol, this amounts to 17.81 per adult man and 7.81 per adult woman, which in turn serves to calculate the average alcohol consumption per day, i.e. $38 \mathrm{~g}$ pure alcohol for men and $17 \mathrm{~g}$ for women. ${ }^{1}$ These figures are well above the amounts set out in the conventional guidelines for low-risk drinking. Most European guidelines set these between 20 and $28 \mathrm{~g} /$ day of pure alcohol for men and 10-14 g/day for women. High-risk drinking is observed in large groups of the Belgian population; meaning there is acceptance of a high risk of disease and injuries. For the majority of alcohol-mediated diseases, the risk rises exponentially in line with higher consumption. ${ }^{5}$

The Belgian Hypertension Committee and other scientific societies report that two million adults in Belgium are hypertensive (one adult over four) and this number will increase to three million by 2025 .

According to the study of Duprez et al., ${ }^{22}$ who studied the prevalence of HTN at worksite, $31.9 \%$ of all men (18-64 years-old) and $23.3 \%$ of all women (18-67 years-old) were hypertensive in Belgium. Among these people, $71 \%$ of men and $67 \%$ of women were unaware; $14 \%$ of men and $19 \%$ of women were treated but blood pressure was not well controlled; while only $14 \%$ of men and $24 \%$ of women were controlled. Similar numbers have been found in other studies all over Europe. In another study from De Backer et al., ${ }^{23}$ the prevalence of HTN in the Belgian general population (16300 men and 5075 women) varied between 
36.2 and $64.1 \%$ for men with an age range of $35-44$ years and 65-74 years, respectively. In women, it varied between 19.3 and $79.9 \%$ in the same age ranges. ${ }^{23}$ Last but not least, in the study of Banegas et al.,$^{24}<50 \%$ of Belgian people treated for HTN were well-controlled, a ratio similar to other European countries.

During the World HTN Day in 2007, Belgian civil employees self-declared HTN in $21.9 \%$ of cases ( $14.3 \%$ in normotensive subjects and $46.8 \%$ in hypertensive subjects). At the same time, they declared a consumption of more than three glasses alcohol per week day in $8.8 \%$ of cases $(6.4 \%$ in normotensive and $16.7 \%$ in hypertensive subjects) and during the weekend in $24.2 \%$ of cases $(20.8 \%$ in normotensive and $34.9 \%$ in hypertensive). ${ }^{25}$

It is estimated that among primary care patients (aged 40-64 years) with HTN, 14.2-19.8\% of men and $14.1-16.1 \%$ of women need a brief intervention for heavy drinking. Overall, $11.1-16.7 \%$ of men and $3.9-5.8 \%$ of women need a formal treatment, on the basis of a study conducted in six European countries in more than 13000 respondents. $^{26}$

\section{Prevention of HTN Through a Reduction of Alcohol Consumption}

Several interventional studies have demonstrated blood pressure-reducing effects of reduced alcohol consumption in both treated and untreated hypertensive patients. ${ }^{19,27}$ A meta-analysis of 15 randomised clinical trials revealed that alcohol reduction in hypertensive patients lowered systolic blood pressure by $3 \mathrm{mmHg}$ and diastolic blood pressure by $2 \mathrm{mmHg}{ }^{28}$ This positive effect was independent of confounding factors such as age, weight and sodium consumption. ${ }^{29}$

Blood pressure reduction by only a few $\mathrm{mmHg}$ in individual patients can lead to relevant changes in cardiovascular morbidity and mortality, in particular when combined with other blood-pressure-reducing measures. Accordingly, a population-wide reduction of systolic blood pressure by $5 \mathrm{mmHg}$ can decrease population-wide stroke-related mortality by $14 \%$, coronary heart disease mortality by $9 \%$, and overall mortality by $7 \% .^{30,31}$

The current common guidelines of the European Society of HTN (ESH) and the European Society of Cardiology (ESC) recommend (recommendation class I, evidence level A) behavioural changes, including reduction of alcohol consumption to a daily maximum consumption of $30 \mathrm{~g}$ for men and $20 \mathrm{~g}$ for women, before initiation of antihypertensive treatment. ${ }^{32}$

Among the generally reported 'lifestyle changes amenable to intervention' are smoking, lack of physical exercise, unhealthy diet, overweight and stress. Alcohol consumption is featured far too rarely on this list, despite the recommendations from the European guidelines ${ }^{32}$ and in Belgium, from the Belgian Social Security System INAMI/RIZIV. ${ }^{33}$

\section{Rationale for Alcohol Screening and Brief Intervention in Primary Care in Belgium}

The WHO has developed a screening procedure, the Alcohol Use Disorders Identification Test (AUDIT) with 10 questions to detect a problem of alcohol use and potential alcohol use disorders. ${ }^{34}$ Depending on the screening results, this leads to three potential follow-up interventions: no demand for action, brief intervention or treatment of alcohol use disorders (by a general practitioner or by a specialist). Meanwhile, a brief screening test (AUDIT-C) with only three questions is often used. ${ }^{35}$ Brief interventions are simple counselling procedures lasting up to 60 minutes, which have the objective to reduce harmful drinking. ${ }^{36}$ Most of the currently used brief interventions last approximately 10 minutes and can be implemented in a repeated session. They are based on motivational procedures. ${ }^{37,38}$

Implementation of alcohol screening followed by a brief intervention, if necessary, for cases of problem consumption and appropriate treatment of alcohol dependence, respectively, may be beneficial to reduce the alcohol-related risk factor, either for the development of HTN or the worsening of HTN in case the patient was already hypertensive. Moreover, such an intervention strategy may also help to improve the blood pressure lowering management in hypertensive patients.

In Belgium, the general practitioner is the one facing the most alcohol-dependent persons and hypertensive patients in their day to day practice. If weight, smoking and stress are regularly evoked by general practitioners with the patients suffering from HTN, the question of alcohol consumption, as a risk factor, is much less frequently evoked. More generally, if the question of smoking is systematically evoked when opening the 'Global Medical Chart' (GMC; Dossier Medical Global in French and Global Medisch Dossier in Flemish) or at the occasion of a yearly check-up (GMC+), the question of alcohol consumption is asked systematically in only $50 \%$ of these circumstances (personal communication of Dr. B. D. Dor on the basis of a survey). There is a need for increasing the awareness regarding the risk of alcohol consumption for HTN among the physicians. They should ask for instance the standard number of alcohol glasses consumed per week. Moreover, the public health authorities and health care insurance companies should also consider more campaigns or providing more information regarding the effect of drinking alcohol, not only in relation to HTN, heart disease and the 
potential risk for cancer, like during the last decade a large effort has been undertaken for the devastating effects of smoking.

An internal survey by the General Medical Practice Scientific Society (GMPSS or SSMG in French), which includes 3000 members, all general practitioners, among the 7500 French-speaking Belgian general practitioners, has shown that the affiliated physicians knew perfectly the thresholds from the WHO and recommended them. This excellent knowledge of WHO thresholds came from the permanent training efforts of the GMPSS, among its members, for a period of 10 years. However, knowing something does not mean implementing the knowledge itself. Important efforts remain to be done in terms of implementation. ${ }^{39}$

The positive impact of screening and brief intervention for a problem of alcohol use in primary care has been demonstrated in different European projects, such as the Optimising Delivery of Health Care Interventions (ODHIN) project and the PHEPA (Primary Health Care European Project on Alcohol) project. Screening and brief intervention successfully reduce average alcohol consumption and episodes of binge drinking. ${ }^{40,41}$ Furthermore there are studies showing that the positive results can be sustainable. ${ }^{42}$ Nevertheless brief interventions are still not established in daily routine practice. To a certain extent, the transfer between randomised and highly controlled studies to clinical practice has failed because of a lack of time in daily routine. ${ }^{43}$

\section{Barriers to Alcohol Screening in Belgium}

The causes of treatment gap in alcohol problems are related to treatments (lack of efficacy, complex treatment regimens with abstinence as unique goal), society (low public awareness of alcohol dependence as a brain disease and of the burden of alcohol consumption), physicians (preference for psychosocial intervention, limited screening, diagnosing and treatment skills in primary care, lack of motivation, social stigma) and patients (low treatment-seeking behaviour due to stigma, negative experience with treatments, treatment is not solving the problem, privacy issues and denial of problem severity).

The median treatment delay after the onset of an alcohol use disorder is 18 years (1 year in $12.8 \%$ of patients). ${ }^{44,45}$

In Belgium, screening and brief interventions for hazardous/harmful drinking is not systematically implemented, neither by primary health care providers, nor in other medical settings, and even in mental health units. The treatment of alcohol dependence is ensured by specialists (in- or outpatients, therapeutic communities, mutual aid and self-help connect with healthcare institutions). There is no treatment monitoring system in place. The health system is decentralised. ${ }^{1}$ A total of $10.2 \%$ of the gross domestic product is spent on healthcare, but only $6.1 \%$ of this total expenditure goes to mental health. Although mental healthcare is largely accessible and offers high levels of quality, it is questionable whether this can be maintained, given the economic climate. The collection of epidemiological data is problematic due to the different ways registration takes place within different care systems and the complexity of the state structure and its consecutive constitutional reforms. Coming from a largely hospital-driven psychiatric care, mental healthcare reforms of past decades have created more community-based care and new care pathways, still an ongoing process. ${ }^{46}$

In a study conducted in six European countries with 770 primary healthcare providers, the main barriers to alcohol screening were time constraints $(77.7 \%)$, lack of training $(34.7 \%)$, lack of services to refer patient to $(33.6 \%)$, lack of familiarity $(27.7 \%)$, risk of upsetting the patient $(21.2 \%)$, lack of financial incentives $(9.3 \%)$ and other reasons $(13.3 \%) .^{47}$

The top five perceived barriers and facilitators of early alcohol intervention by European general practitioners have been summarised in Table $1 .{ }^{48}$

Table 1 Top five perceived barriers and facilitators of early alcohol intervention by European general practitioners.

\begin{tabular}{|c|c|c|}
\hline Ranking & Top five perceived barriers & Percentage \\
\hline 1 & Doctors are just too busy dealing with the problems people present with & 64.3 \\
\hline 2 & Doctors are not trained in counselling for reducing alcohol consumption & 52.1 \\
\hline 3 & $\begin{array}{l}\text { Doctors believe that alcohol counselling involves family and wider social effects, } \\
\text { and is therefore too difficult }\end{array}$ & 49.7 \\
\hline 4 & General practices are not organised to do preventive counselling & 48.6 \\
\hline 5 & $\begin{array}{l}\text { Doctors do not believe that patients would take their advice and change their behaviour } \\
\text { Top five perceived facilitators }\end{array}$ & 47.6 \\
\hline 1 & Support services (self-help/counselling) were readily available to refer patients to & 83.7 \\
\hline 2 & Patients requested health advice about alcohol consumption & 80.1 \\
\hline 3 & Quick and easy counselling materials were available & 75.4 \\
\hline 4 & Training programmes for early intervention for alcohol were available & 75.3 \\
\hline 5 & Early intervention for alcohol was proven to be successful & 73.2 \\
\hline
\end{tabular}

According to Optimising Delivery of Health Care Interventions (ODHIN): survey of attitudes and managing alcohol problems in general practice in Europe - final report. http://www.odhinproject.eu. 2015. 
Several difficulties influence the implementation of screening and brief intervention for alcohol. They have been identified and listed in Table 2 .

\section{Benefits for the Healthcare Service}

Reduction of morbidity and mortality related to HTN and alcohol consumption results in considerable costs savings to the healthcare services. ${ }^{49,50}$

With the model (as shown in Fig. 1) for Belgium, we could potentially save 16.7 and $14.7 \%$ of HTN cases in men and women, respectively. With a more conservative approach, we could potentially save 15.9 and $13.4 \%$ of cases in men and women, respectively.

\section{Future Perspectives}

There is a vast potential for prevention and/or healthcare improvement for hypertensive patients with hazardous or harmful alcohol use, which has not been sufficiently exploited. The expert group believes that early identification through alcohol screening and brief intervention in general practice can help to improve the management of hypertensive patients, to reach (the aforementioned) targets of the WHO Global Action Plan aimed at reducing alcohol consumption and the prevalence of HTN, and thus also achieve major savings in the healthcare service.

Based on the review of the situation and clinical evidence in Belgium, the experts proposed a specific goal and key steps required to reach this goal.

The goal agreed for Belgium was: 'Early identification and brief intervention for alcohol use, and treatment or referral for alcohol problematic use in patients with HTN in ambulatory care'.

\section{Table 2 Difficulties influencing the implementation of screening and brief intervention for alcohol.}

Working with multiple definitions of problematic drinking; lack of clear guidance

Alcohol being an emotive issue

Misunderstanding of the implications of the potential protective effect of alcohol

The doctor's own relationship with alcohol can be a potential barrier to open discussion, or a facilitator to empathy

Users find that discussing drinking is facilitated by a good relationship with the health professional, whereas providers are concerned not to offend users in relation to discussing alcohol for fear of disturbing the therapeutic relationship

Organisational factors such as adequate support and resources can influence the acceptability and implementation of screening and brief intervention for hazardous and harmful alcohol use

Positive support from governments, management and involvement of non-clinical members of staff are more likely to result in successful implementation

There is also evidence that adequate practitioner training and support in screening and use of brief intervention materials facilitates effective implementation as well as rates and appropriate detection of at risk drinkers

Financial incentives and successful management of staff changes as well as assistance from receptionists are also important.

However, barriers to success included competing priorities and lack of time

In general, training rates are low, and practitioners themselves perceive a lack of training

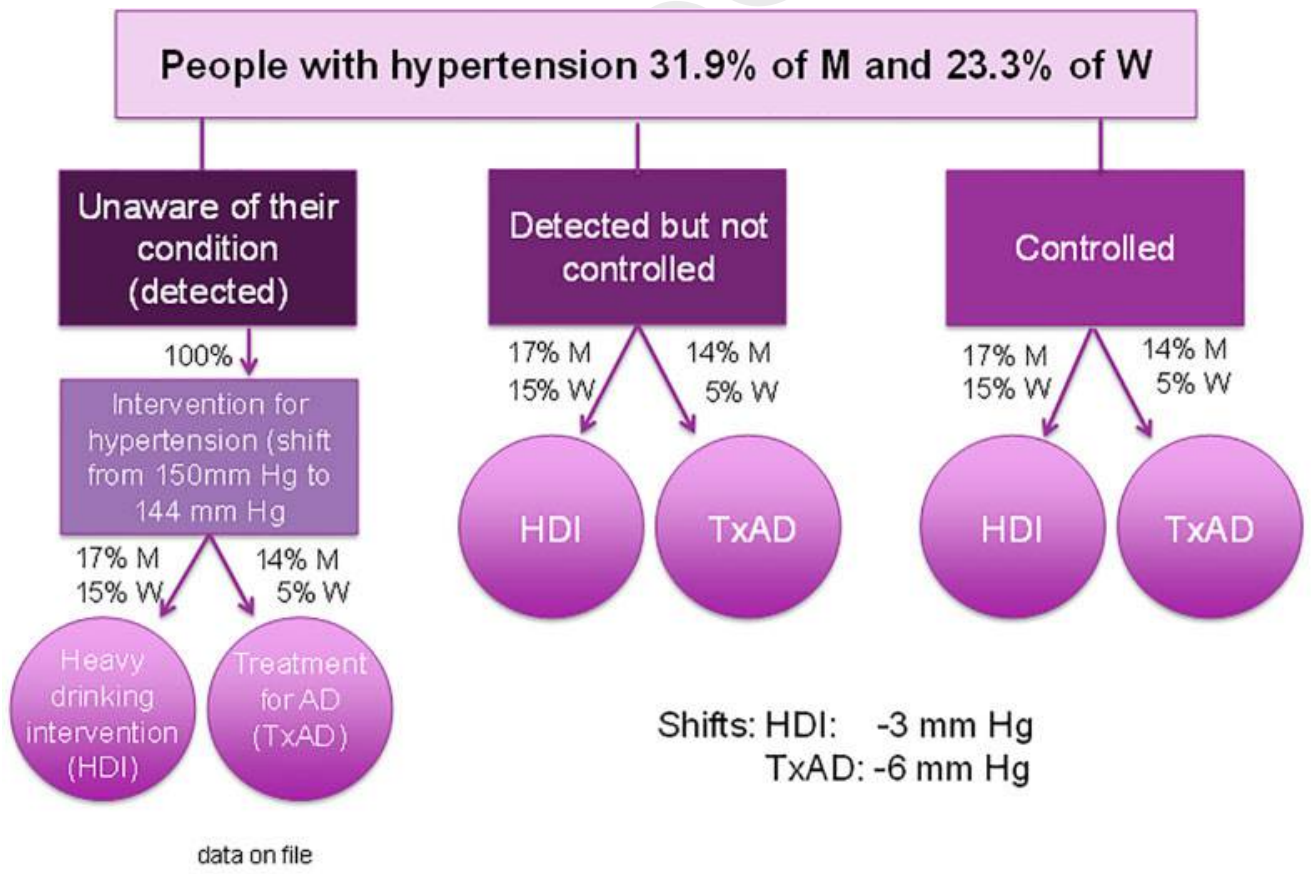

$\mathrm{M}=\mathrm{Man}: \mathrm{W}=$ Woman $; \mathrm{HDI}=$ Heavy Drinking Intervention $; \mathrm{AD}=$ Alcohol Disorder $; \mathrm{TxAD}=$ Treatment for Alcohol Disorder

Figure 1 Model of the shift in systolic blood pressure of Belgian people with arterial HTN and alcohol disorders, depending on gender, on the awareness and control of HTN, and on the treatment of the alcohol disorder. M: man; W: woman; HDI: heavy drinking intervention; AD: alcohol disorder; TxAD: treatment for alcohol disorder. 
Table 3 Expert working groups (WGs) responsible for proposing an action plan to help all key stakeholders, achieving the goal of early identification and brief intervention for alcohol use, and treatment or referral for alcohol problematic use in patients with hypertension (HTN) in ambulatory care

\begin{tabular}{ll}
\hline WG number & WG focus \\
\hline 1 & $\begin{array}{l}\text { Incentives for physician's training and for time } \\
\text { Incentives for patients }\end{array}$ \\
2 & Education of health professionals: general practitioners and specialists \\
3 & Public education: awareness and anti-stigmatisation \\
5 & Screening: tools of severity assessment and integration of existing tools \\
6 & Evidence for the efficacy of brief interventions and patterns of drinking \\
7 & Improvement of interventions: personalisation, indication of treatment by \\
8 & severity and prioritisation of lifestyle changes \\
& Healthcare system: collaboration, analyses of changes, referral and increase \\
\hline
\end{tabular}

The experts in Belgium then identified a number of distinct areas for improvement that would help healthcare professionals, and other key stakeholders, to achieve this goal. For each of these areas, the experts established a working group consisting of a leader and one or more members, who would develop concrete action plans to address the goal and key steps identified to reach that goal (Table 3).

\section{Acknowledgements}

The authors are grateful to Jacques Bruhwyler, PhD (ECSOR sa/nv), who provided medical writing assistance for the preparation of the manuscript.

\section{Disclaimer statements}

\section{Contributors}

Funding All authors are experts in alcohol or hypertension. They met in Brussels on the 2nd of June 2014 to review the current situation regarding the management of hypertension and alcohol use disorders in Belgium and to set up a pragmatic way of moving forward to deal with these issues. All authors contributed to the content and the writing of the paper.

Conflict of interest The meeting was supported by Lundbeck and members of the working group received an attendance honorarium. However, no member of the working group received any remuneration for the preparation of this manuscript.

\section{Ethics approval}

\section{References}

1 World Health Organization. Global action plan for the prevention and control of noncommunicable diseases, 2013-2020. Geneva, Switzerland: WHO; 2013.

2 GBD 2013 Mortality and Causes of Death Collaborators. Global, regional, and national age-sex specific all-cause and cause-specific mortality for 240 causes of death, 1990-2013: a systematic analysis for the Global Burden of Disease Study 2013. Lancet. 2015;385(9963):117-71.

3 World Health Organization. Global status report on alcohol and health. Geneva: WHO; 2014.
4 Rehm J, Samokhvalov AV, Neuman MG, Room R, Parry C, Lonnroth $\mathrm{K}$, et al. The association between alcohol use, alcohol use disorders and tuberculosis (TB). A systematic review. BMC Public Health. 2009;9:450

5 Rehm J, Baliunas D, Borges GL, Graham K, Irving H, Kehoe T, et al. The relation between different dimensions of alcohol consumption and burden of disease: an overview. Addiction. 2010;105(5):817-43.

6 Matsumoto C, Miedema MD, Ofman P, Gaziano JM, Sesso HD. An expanding knowledge of the mechanisms and effects of alcohol consumption on cardiovascular disease. J Cardiopulm Rehabil Prev. 2014;34(3):159-71

7 Nichols M, Scarborough P, Allender S, Rayner M. What is the optimal level of population alcohol consumption for chronic disease prevention in England? Modelling the impact of changes in average consumption levels. BMJ Open. 2012;2(3):e000957.

8 Rehm J, Lachenmeier DW, Room R. Why does society accept a higher risk for alcohol than for other voluntary or involuntary risks? BMC Med. 2014;12:189.

9 Shield KD, Parry C, Rehm J. Chronic diseases and conditions related to alcohol use. Alcohol Res. 2013;35(2):155-73.

10 Rehm J, Sempos CT, Trevisan M. Alcohol and cardiovascular disease - more than one paradox to consider. Average volume of alcohol consumption, patterns of drinking and risk of coronary heart disease - a review. J Cardiovasc Risk. 2003;10(1):15-20.

11 Klatsky AL, Friedman GD, Armstrong MA, Kipp H. Wine, liquor, beer, and mortality. Am J Epidemiol. 2003;158(6):585-95.

12 Rimm EB, Klatsky A, Grobbee D, Stampfer MJ. Review of moderate alcohol consumption and reduced risk of coronary heart disease: is the effect due to beer, wine, or spirits. BMJ. 1996;312(7033):731-6.

13 Molina PE, Gardner JD, Souza-Smith FM, Whitaker AM. Alcohol abuse: critical pathophysiological processes and contribution to disease burden. Physiology. 2014;29(3):203-15.

14 Dugernier T, Starkel P, Laterre PF, Reynaert MS. Severe acute pancreatitis: pathophysiologic mechanisms underlying pancreatic necrosis and remote organ damage. Acta Gastroenterol Belg. 1996;59(3):178-85.

15 World Health Organization. A global brief on hypertension. Why hypertension is a major public health issue. Geneva: WHO; 2013

16 Briasoulis A, Agarwal V, Messerli FH. Alcohol consumption and the risk of hypertension in men and women: a systematic review and meta-analysis. J Clin Hypertens (Greenwich). 2012;14(11):792-8.

17 Taylor B, Irving HM, Baliunas D, Roerecke M, Patra J, Mohapatra S, et al. Alcohol and hypertension: gender differences in dose-response relationships determined through systematic review and meta-analysis. Addiction. 2009;104(12):1981-90.

18 Malhotra H, Mehta SR, Mathur D, Khandelwal PD. Pressor effects of alcohol in normotensive and hypertensive subjects. Lancet. 1985;2(8455):584-6.

19 Puddey IB, Beilin LJ, Vandongen R. Regular alcohol use raises blood pressure in treated hypertensive subjects. A randomised controlled trial. Lancet. 1987;1(8534):647-51.

20 Rosito GA, Fuchs FD, Duncan BB. Dose-dependent biphasic effect of ethanol on 24-h blood pressure in normotensive subjects. Am J Hypertens. 1999;12(2 Pt 1):236-40. 
21 Stranges S, Wu T, Dorn JM, Freudenheim JL, Muti P, Farinaro E, et al. Relationship of alcohol drinking pattern to risk of hypertension: a population-based study. Hypertension. 2004;44(6):813-9.

22 Duprez D, Van HP, Van den Eynde W, Leeman M. Prevalence of hypertension in the adult population of Belgium: report of a worksite study, attention hypertension. J Hum Hypertens 2002:16(1):47-52.

23 De Bacquer D, De Backer G. The prevalence of concomitant hypertension and hypercholesterolaemia in the general population. Int J Cardiol. 2006;110(2):217-23.

24 Banegas JR, Lopez-Garcia E, Dallongeville J, Guallar E, Halcox JP, Borghi C, et al. Achievement of treatment goals for primary prevention of cardiovascular disease in clinical practice across Europe: the EURIKA study. Eur Heart J. 2011;32(17):2143-52.

25 Van der Niepen P, Van de Borne P, Persu A, Andries A. Prevalence of hypertension and cardiovascular risk factors in Belgian civil employees: results of the screening during World Hypertension Day 2007. J Hypertens. 2008;26(5):1045-6.

26 Rehm J, Gmel G, Kiefer F, Kreutz R, Kugler J, MullerWalther $\mathrm{M}$, et al. [Improvement of management of hypertension by implementation of alcohol screening and subsequent interventions in primary practice]. Dtsch Med Wochenschr. 2014:139(48):2457-62.

27 Ueshima H, Mikawa K, Baba S, Sasaki S, Ozawa H, Tsushima M, et al. Effect of reduced alcohol consumption on blood pressure in untreated hypertensive men. Hypertension. 1993;21(2):248-52.

28 Xin X, He J, Frontini MG, Ogden LG, Motsamai OI, Whelton PK. Effects of alcohol reduction on blood pressure: a metaanalysis of randomized controlled trials. Hypertension. 2001;38(5):1112-7.

29 Okubo Y, Suwazono Y, Kobayashi E, Nogawa K. Alcohol consumption and blood pressure change: 5-year follow-up study of the association in normotensive workers. J Hum Hypertens. 2001;15(6):367-72.

30 Stamler R. Implications of the INTERSALT study. Hypertension. 1991;17(1 Suppl):I16-I20.

31 Whelton PK, He J, Appel LJ, Cutler JA, Havas S, Kotchen TA, et al. Primary prevention of hypertension: clinical and public health advisory from The National High Blood Pressure Education Program. JAMA. 2002;288(15):1882-8.

32 ESH/ESC Task Force for the Management of Arterial Hypertension. Practice guidelines for the management of arterial hypertension of the European Society of Hypertension (ESH) and the European Society of Cardiology (ESC): ESH/ESC Task Force for the Management of Arterial Hypertension. $\underline{\mathbf{J}}$ Hypertens. 2013;31(10):1925-38.

33 Institut National d'Assurance Maladie Invalidité/Rijksinstituut Voor Ziekte- en Invaliditeitsverzekering. Traitement Efficient de l'Hypertension Compliquée. Brussels, Belgium 2004

34 Reinert DF, Allen JP. The alcohol use disorders identification test (AUDIT): a review of recent research. Alcohol Clin Exp Res. 2002;26(2):272-9.

35 Bush K, Kivlahan DR, McDonell MB, Fihn SD, Bradley KA, The AUDIT. alcohol consumption questions (AUDIT-C): an effective brief screening test for problem drinking. Ambulatory care quality improvement project (ACQUIP). Alcohol Use Disorders Identification Test. Arch Intern Med. 1998;158(16):1789-95.

36 Babor TF, McRee BG, Kassebaum PA, Grimaldi PL, Ahmed $\mathrm{K}$, Bray J. Screening, brief intervention, and referral to treatment (SBIRT): toward a public health approach to the management of substance abuse. Subst Abus. 2007;28(3):7-30.

37 Kohler S, Hofmann A. Can motivational interviewing in emergency care reduce alcohol consumption in young people? A systematic review and meta-analysis. Alcohol Alcohol. 2015;50(2):107-17.

38 Klimas J, Tobin H, Field CA, O'Gorman CS, Glynn LG, Keenan E, et al. Psychosocial interventions to reduce alcohol consumption in concurrent problem alcohol and illicit drug users. Cochrane Database Syst Rev. 2014;12:CD009269.

39 Dor B. Opportunities and challenges of alcohol screening and intervention in hypertensive patients from a primary care perspective. Screening and intervention for harmful alcohol use as a tool to improve the management of hypertension in primary care, Expert Roundtable Meeting, Brussels, Belgium ed, 2014.

40 Kaner EF, Beyer F, Dickinson HO, Pienaar E, Campbell F, Schlesinger $\mathrm{C}$, et al. Effectiveness of brief alcohol interventions in primary care populations. Cochrane Database Syst Rev. 2007;2:CD004148.

41 O'Donnell A, Anderson P, Newbury-Birch D, Schulte B, Schmidt C, Reimer J, et al. The impact of brief alcohol interventions in primary healthcare: a systematic review of reviews. Alcohol Alcohol. 2014;49(1):66-78.

42 Ornstein SM, Miller PM, Wessell AM, Jenkins RG, Nemeth LS, Nietert PJ. Integration and sustainability of alcohol screening, brief intervention, and pharmacotherapy in primary care settings. J Stud Alcohol Drugs. 2013;74(4):598-604.

43 Heather N. The efficacy-effectiveness distinction in trials of alcohol brief intervention. Addict Sci Clin Pract. 2014;9:13.

44 Bruffaerts R, Bonnewyn A, Demyttenaere K. Troubles psychiques en Belgique au debut du XXI siecle. Etat des lieux et reflexions pour lavenir: état des lieux et réflections pour l'avenir. Acco ed. 2012.

45 Stein DJ, Aguilar-Gaxiola S, Alonso J, Bruffaerts R, de JP, Liu $\mathrm{Z}$, et al. Associations between mental disorders and subsequent onset of hypertension. Gen Hosp Psychiatry. 2014;36(2):142-9.

46 Hermans MH, De WN, Dom G. The state of psychiatry in Belgium. Int Rev Psychiatry. 2012;24(4):286-94.

47 Drummond C, Wolstenholme A, DeLuca P, Davey Z, Donoghue K, Elzerbi C. Alcohol interventions and treatments in Europe. In: Anderson P, Braddick F, Reynolds J, Gual A, editors. 2nd. Barcelona: Amphora; 2013; p. 65-80.

48 ODHIN. Optimizing delivery of health care interventions: survey of attitudes and managing alcohol problems in general practice in Europe - final REPORT. Available from: http://www.od hinproject.eu 2015.

49 Roerecke M, Rehm J. Alcohol intake revisited: risks and benefits. Curr Atheroscler Rep. 2012;14(6):556-62.

50 Singh JK, Ranjan P, Kumari A, Dahale AS, Jha R, Das R. Types, outcome and risk factors of stroke in tribal patients. Int J Stroke. 2013;8(8):675-80. 